\title{
Outcomes after implantation of partial-support left ventricular assist devices in inotropic-dependent patients: Do we still need full-support assist devices?
}

\author{
Anton Sabashnikov, MD, ${ }^{\mathrm{a}, \mathrm{b}}$ Aron-Frederik Popov, MD, PhD, ${ }^{\mathrm{a}}$ Christopher T. Bowles, PhD, ${ }^{\mathrm{a}}$ \\ Prashant N. Mohite, MCh, ${ }^{\mathrm{a}}$ Alexander Weymann, MD, PhD, ${ }^{\mathrm{a}}$ Rachel Hards, BS, ${ }^{\mathrm{a}}$ Mike Hedger, BS, ${ }^{\mathrm{a}}$ \\ Thorsten Wittwer, MD, PhD, ${ }^{b}$ Jens Wippermann, MD, PhD, ${ }^{b}$ Thorsten Wahlers, MD, PhD, ${ }^{b}$ \\ Friedrich A. Schoendube, $\mathrm{MD}, \mathrm{PhD},{ }^{\mathrm{c}}$ and André R. Simon, $\mathrm{MD}, \mathrm{PhD}^{\mathrm{a}}$
}

\begin{abstract}
Objectives: Partial-support left ventricular assist devices (LVADs) represent a novel strategy for heart failure treatment. The Synergy Pocket Micro-pump (HeartWare Inc, Framingham, Mass), the smallest surgically implanted long-term LVAD, provides partial flow up to $4.25 \mathrm{~L} / \mathrm{min}$ and was primarily designed for "less sick" patients with severe heart failure. This device is implanted minimally invasively without sternotomy or cardiopulmonary bypass. Early implantation in patients with Interagency Registry for Mechanically Assisted Circulatory Support class 4 and higher was shown to be feasible and associated with significantly improved hemodynamics and quality of life. The aim of this study was to present our experience with implementation of long-term partial circulatory support as a bridge to transplantation in patients with more advanced heart failure who were dependent preoperatively on inotropic support or intra-aortic balloon pump.
\end{abstract}

Methods: In this observational study, only inotropic or intra-aortic balloon pump-dependent patients with endstage heart failure were included $(\mathrm{n}=12)$. These patients underwent Synergy device implantation between February 2012 and August 2013.

Results: The mean preoperative Interagency Registry for Mechanically Assisted Circulatory Support class was $2.17 \pm 0.84$ (class $1,25 \%$; class $2,33 \%$; class $3,42 \%$ ). The mean age was $46 \pm 15$ years, and $33 \%$ were female. Preoperatively, 4 patients $(33 \%)$ had at least 1 previous sternotomy, 3 patients $(25 \%)$ were supported with a balloon pump, 1 patient $(8 \%)$ had a previous full-support LVAD, and 4 patients $(33 \%)$ had cerebrovascular events in the past. After device implantation, there were no right ventricular failures, device-related infections, hemorrhagic strokes, arterial or venous thromboembolisms, or worsenings of aortic and mitral regurgitation observed over the follow-up. The mean follow up was $174 \pm 171$ days (range, 5-764 days; cumulative, 3199 days). One patient ( $8 \%$ ) died, 3 patients $(25 \%)$ successfully underwent transplantation, 1 device $(8 \%)$ was explanted after myocardial recovery, and 5 patients $(42 \%)$ are still on ongoing support. Two patients $(17 \%)$ were upgraded to a full-support LVAD after 65 days of mean support. A total of 11 of 12 patients $(92 \%)$ were discharged from the hospital and are presently alive. Left ventricular end-diastolic diameter was significantly reduced 3 months after device implantation.

Conclusions: Partial LVAD support may be clinically efficacious in inotropic and intra-aortic balloon pumpdependent patients. On the basis of our experience and evidence of previous research, such patients may benefit from minimally invasive access, no need for sternotomy and cardiopulmonary bypass, a short implantation time, an easy exchange if necessary, and a lower risk of subsequent heart transplantation. Because the implantation is performed without sternotomy, device upgrade is feasible with a comparatively low operative risk and good clinical outcome. Our preliminary results show that partial-support devices may have the potential to replace fullsupport LVADs in the near future. (J Thorac Cardiovasc Surg 2014;148:1115-22)

\footnotetext{
From the Department of Cardiothoracic Transplantation and Mechanical Circulatory Support, ${ }^{\text {a }}$ Royal Brompton \& Harefield NHS Foundation Trust, Harefield Hospital, Harefield, Middlesex, United Kingdom; Department of Cardiothoracic Surgery, ${ }^{\mathrm{b}}$ University Hospital of Cologne, Cologne, Germany; and Department of Thoracic and Cardiovascular Surgery, ${ }^{c}$ University of Goettingen, Goettingen, Germany.

Disclosures: Authors have nothing to disclose with regard to commercial support. Read at the 94th Annual Meeting of The American Association for Thoracic Surgery, Toronto, Ontario, Canada, April 26-30, 2014.
}

Received for publication April 28, 2014; revisions received April 28, 2014; accepted for publication May 22, 2014.

Address for reprints: Anton Sabashnikov, MD, Department of Cardiothoracic Transplantation and Mechanical Circulatory Support, Royal Brompton \& Harefield NHS Foundation Trust, Hill End Rd, Harefield, Middlesex, UB9 6JH, United Kingdom (E-mail: a.sabashnikov@rbht.nhs.uk) $0022-5223 / \$ 36.00$

Copyright (C) 2014 by The American Association for Thoracic Surgery http://dx.doi.org/10.1016/j.jtcvs.2014.05.063 


$\begin{array}{ll}\text { Abbreviations and Acronyms } \\ \text { IABP } & =\text { intra-aortic balloon pump } \\ \text { INR } & \text { international normalized ratio } \\ \text { INTERMACS }= & \text { Interagency Registry for } \\ & \text { Mechanically Assisted Circulatory } \\ & \text { Support } \\ \text { LVAD } & =\text { left ventricular assist device } \\ \text { RVF } & \text { right ventricular failure }\end{array}$

Cardiac transplantation remains the gold standard therapy for patients with end-stage heart failure. However, because of significantly restricted donor organ availability in a number of countries resulting in increased waiting times and mortality, ${ }^{1}$ left ventricular assist devices (LVADs) are increasingly being applied as a life-sustaining bridge to transplantation. ${ }^{2,3}$ Over the last 2 decades, major technologic improvements in mechanical circulatory support have been achieved, leading to the development of significantly smaller and more reliable continuous-flow systems. ${ }^{4}$ In addition to these full-support devices that can provide up to $10 \mathrm{~L} / \mathrm{min}$ of flow, partial-support devices recently became available.

The Synergy Pocket Micro-pump (HeartWare Inc, Framingham, Mass) is the smallest surgically implanted long-term LVAD, provides partial flow up to $4.25 \mathrm{~L} / \mathrm{min}$, and was designed for patients with severe heart failure without inotropic dependence (Interagency Registry for Mechanically Assisted Circulatory Support [INTERMACS] class 4-7). ${ }^{5}$ Early implantation of this partial-support device in such patients was shown to be feasible and associated with significantly improved hemodynamics, end-organ perfusion, and quality of life. In the majority of patients, the device prevented progression to end-stage heart failure. ${ }^{5-7}$ One of the most important benefits of this device is that it can be implanted with minimally invasive access with no need for sternotomy, resulting in fewer postoperative adverse events.

In view of the reports of the successful treatment of lowrisk patients with the Synergy Pocket Micro-pump, the question arises as to whether patients eligible for a fullsupport LVAD also would benefit from the Synergy device as a bridge to transplantation. The aim of this study was to present the outcomes of inotropic-dependent patients undergoing long-term partial support as a bridge to transplantation.

\section{PATIENTS AND METHODS \\ Study Population}

The study design was a retrospective review of the prospectively collected data and did not require ethical approval. Data were collected from the UK national ventricular assist device database. Twelve consecutive patients dependent on an inotropic or intra-aortic balloon pump (IABP) were included who underwent long-term support with the Synergy
LVAD between July 2007 and August 2013 in Harefield Hospital and University Hospital Goettingen. Implantation strategy was as a bridge to transplantation for therapy-refractory end-stage heart failure. Prospectively collected data included detailed information on patients' demographics and baseline clinical characteristics, laboratory, echocardiographic and hemodynamic parameters, and intraoperative variables and postoperative outcomes.

\section{Definitions}

Liver failure was defined as a 2-fold elevation of the upper limit of the normal range of at least 2 liver function parameters. Any postoperative renal dysfunction that required dialysis/hemofiltration was defined as renal failure. Respiratory failure was defined as any impairment of respiratory function requiring reintubation or mechanical ventilation after LVAD implantation. Right ventricular failure (RVF) was defined as impairment of right-sided function resulting in the need for a short-term or long-term right ventricular assist device.

\section{Surgical Techniques}

All Synergy Pocket Micro-pump implantations were performed offpump as described previously. ${ }^{2,3,6,7}$ Preparation for left atrial cannulation was performed by exposure of the confluence of the right pulmonary veins through a 7 - to $10-\mathrm{cm}$ right-sided thoracotomy in the fourth intercostal space. In all cases, the pericardium was opened directly over the pulmonary veins to provide direct access to the cannulation area. An additional 4-cm subclavicular incision was made for the formation of a small subcutaneous pocket. The pump was then placed in the subcutaneous tissue inferior to the subclavian artery and frontal to the right pectoralis major muscle. After heparin administration, a silicone inflow cannula with a titanium tip and Dacron cuff was inserted into the left atrium using the Seldinger technique between the insertions of the right upper and lower pulmonary veins and secured with two 4-0 polypropylene purse string sutures. The proximal end of the cannula was tunneled through the second intercostal space to the subcutaneous pocket. A polytetrafluoroethylene outflow graft was used to perform an end-to-side anastomosis to the right subclavian artery. After retrograde de-airing of the pump, the proximal end of the inflow graft was connected to the device and the pump was started. Under echocardiographic monitoring, the pump speed was then gradually increased from $20,000 \mathrm{rpm}$ to a maximum of $28,000 \mathrm{rpm}$. While increasing the speed of the device, pump current, cardiac output, pulmonary artery wedge pressure, and arterial pressure were monitored with echocardiographic visualization of the flow from the left atrium into the device. After setting up the final speed and flow at approximately $3 \mathrm{~L} / \mathrm{min}$, the surgical wounds were closed using the standard method.

\section{Driveline Placement}

In all cases, the percutaneous driveline was externalized after a short subfascial course directly under the right subcostal margin.

\section{Anticoagulation Protocol}

Intravenous heparin was administered postoperatively after a minimum of 12 hours as a continuous infusion to progressively increase activated partial thromboplastin time to 50 to 70 seconds when the cumulative chest tube drainage decreased to less than $50 \mathrm{~mL} / \mathrm{h}$ and the coagulation profile returned to near normal levels. Platelet aggregation inhibitors were used as a part of the anticoagulation protocol; $75 \mathrm{mg}$ of aspirin and $75 \mathrm{mg}$ of clopidogrel daily were immediately started after extubation. After chest drain removal and tolerating oral medication, warfarin was administered to maintain the international normalized ratio (INR) between 2.5 and 3.5. The heparin infusion was continued until the INR range was attained. In cases when INR decreased to less than 2.5 and patients were not on heparin infusion, low-molecular heparin was used in a usual dose of $1.5 \mathrm{mg} / \mathrm{kg}$ body weight to ensure an appropriate anticoagulation status during this time period. 
TABLE 1. Patient demographics and preoperative baseline characteristics

\begin{tabular}{lc}
\hline \multicolumn{1}{c}{ Characteristics } & Value \\
\hline Demographic data & \\
Age (y) & $46.1 \pm 14.6$ \\
Female & $4(33.3 \%)$ \\
Height (cm) & $171.3 \pm 8.3$ \\
Weight (kg) & $78.9 \pm 17.1$ \\
Primary diagnosis & \\
DCM & $8(66.7 \%)$ \\
ICM & $4(33.3 \%)$ \\
Comorbidities & \\
Hypertension & $3(25 \%)$ \\
COPD & $3(25 \%)$ \\
Diabetes mellitus & $2(16.7 \%)$ \\
PVD & 0 \\
History of cerebrovascular events & $4(33.3 \%)$ \\
History of cardiac arrest & $1(8.3 \%)$ \\
Other clinical data & \\
Time since first cardiac diagnosis (mo) & $115 \pm 79$ \\
Previous sternotomy & $4(33.3 \%)$ \\
Previous thoracotomy & $1(8.3 \%)$ \\
Previous acute MI & $4(33.3 \%)$ \\
Mechanical ventilation & $1(8.3 \%)$ \\
Hemodialysis & $1(8.3 \%)$ \\
Ascites & 0 \\
ICD & $8(66.7 \%)$ \\
Current smoker & $2(16.7 \%)$ \\
INTERMACS class & $3(25 \%)$ \\
1 & $4(33.3 \%)$ \\
2 & $5(41.7 \%)$ \\
\hline & \\
\hline &
\end{tabular}

COPD, Chronic obstructive pulmonary disease; DCM, dilated cardiomyopathy; ICD, internal cardioverter defibrillator; ICM, ischemic cardiomyopathy; INTERMACS, Interagency Registry for Mechanically Assisted Circulatory Support; $M I$, myocardial infarction; $P V D$, peripheral vascular disease.

\section{Statistical Analysis}

All data were analyzed using the Statistical Package for Social Sciences version 21.0 (SPSS Inc, Chicago, Ill) and are presented as continuous or categoric variables. Continuous data were evaluated for normality using 1-sample Kolmogorov-Smirnov test and confirmed by histograms. Continuous variables were expressed as the mean \pm standard deviation in cases of normal distributed variables or median (interquartile range) in cases of nonnormally distributed variables. Categoric variables are presented as total numbers of patients and percentages. Laboratory test changes over the perioperative course were analyzed with paired $t$ test for normally distributed variables. Kaplan-Meier survival estimation was applied for survival analysis of the entire patient cohort. Patients who underwent cardiac transplantation, device exchange for device failure, or device explantation for myocardial recovery were censored.

\section{RESULTS}

Patient demographics and preoperative baseline characteristics are presented in Table 1 . The mean age of the study cohort was $46.1 \pm 14.6$ years, and $33.3 \%$ of patients were female. Dilated cardiomyopathy was the primary diagnosis in the majority of patients $(66.7 \%)$, followed by ischemic
TABLE 2. Patient preoperative hemodynamic and echocardiographic parameters

\begin{tabular}{|c|c|}
\hline Characteristics & Value \\
\hline \multicolumn{2}{|l|}{ MCS } \\
\hline IABP support & $3(25.0 \%)$ \\
\hline Previous full-flow LVAD support & $1(8.3 \%)$ \\
\hline \multicolumn{2}{|l|}{ Hemodynamic status } \\
\hline Inotropic support & $12(100 \%)$ \\
\hline Milrinone & $8(66.7 \%)$ \\
\hline Dobutamine & $3(25.0 \%)$ \\
\hline Adrenaline & $2(16.7 \%)$ \\
\hline Noradrenaline & $2(16.7 \%)$ \\
\hline Levosimendan & $1(8.3 \%)$ \\
\hline Arrhythmia & $3(25.0 \%)$ \\
\hline Heart rate (beats/min) & $88.6 \pm 16.2$ \\
\hline QRS-complex duration (ms) & $143.6 \pm 10.4$ \\
\hline $\mathrm{CVP}(\mathrm{mm} \mathrm{Hg})$ & $12.1 \pm 6.6$ \\
\hline MPAP (mm Hg) & $37.7 \pm 13.8$ \\
\hline Wedge $(\mathrm{mm} \mathrm{Hg})$ & $25.1 \pm 5.6$ \\
\hline $\mathrm{CI}\left(\mathrm{L} / \mathrm{m}^{2}\right)$ & $1.9 \pm 0.8$ \\
\hline $\mathrm{SvO}_{2}(\%)$ & $66.7 \pm 10.2$ \\
\hline Lactate $(\mathrm{mmol} / \mathrm{L})$ & $1.5 \pm 0.4$ \\
\hline \multicolumn{2}{|l|}{ Echocardiographic parameters } \\
\hline $\operatorname{LVEDD}(\mathrm{mm})$ & $71.8 \pm 9.2$ \\
\hline $\operatorname{LVESD}(\mathrm{mm})$ & $65.3 \pm 9.8$ \\
\hline $\mathrm{EF}(\%)$ & $21.1 \pm 11.1$ \\
\hline \multicolumn{2}{|l|}{ MR (grade) } \\
\hline No & 0 \\
\hline Trivial & $6(50 \%)$ \\
\hline Mild & $4(33.3 \%)$ \\
\hline Moderate & 0 \\
\hline Severe & $2(16.7 \%)$ \\
\hline \multicolumn{2}{|l|}{ TR (grade) } \\
\hline No & $1(8.3 \%)$ \\
\hline Trivial & $5(41.7 \%)$ \\
\hline Mild & $3(25.0 \%)$ \\
\hline Moderate & 0 \\
\hline Severe & $3(25.0 \%)$ \\
\hline \multicolumn{2}{|l|}{ AR (grade) } \\
\hline No & $6(50.0 \%)$ \\
\hline Trivial & $6(50.0 \%)$ \\
\hline Mild & 0 \\
\hline Moderate & 0 \\
\hline Severe & 0 \\
\hline
\end{tabular}

$A R$, Aortic valve regurgitation; $C I$, cardiac index; $C V P$, central venous pressure; $E F$ ejection fraction; $I A B P$, intra-aortic balloon pump; $L V A D$, left ventricular assist device; $L V E D D$, left ventricular end-diastolic diameter; $L V E S D$, left ventricular end-systolic diameter; $M P A P$, mean pulmonary artery pressure; $M R$, mitral valve regurgitation; $\mathrm{MCS}$, mechanical circulatory support; $\mathrm{SvO}_{2}$, central venous saturation; $T R$, tricuspid valve regurgitation.

cardiomyopathy $(33.3 \%)$. Patients with congenital heart defects, peripartum dilated cardiomyopathy, and hypertrophic obstructive cardiomyopathy were not present in our cohort. Inotropic support was started in all patients preoperatively to maintain acceptable end-organ function. Nevertheless, only $41.7 \%$ remained relatively stable, whereas $33.3 \%$ had progressive deterioration in hemodynamics 
TABLE 3. Patient preoperative laboratory parameters

\begin{tabular}{lc}
\hline \multicolumn{1}{c}{ Characteristics } & Value \\
\hline Laboratory parameters & \\
BNP $(\mathrm{pg} / \mathrm{mL})$ & $1597 \pm 1016$ \\
Sodium $(\mathrm{mmol} / \mathrm{L})$ & $135.3 \pm 3.1$ \\
Potassium $(\mathrm{mmol} / \mathrm{L})$ & $4.4 \pm 0.8$ \\
BUN $(\mathrm{mg} / \mathrm{dL})$ & $9.6 \pm 2.6$ \\
Creatinine $(\mathrm{mmol} / \mathrm{L})$ & $92.3 \pm 19.8$ \\
GFR & $54.5 \pm 20.5$ \\
Albumin $(\mathrm{g} / \mathrm{L})$ & $37 \pm 6.0$ \\
Total bilirubin $(\mathrm{mmol} / \mathrm{L})$ & $27.9 \pm 28.9$ \\
INR & $1.4 \pm 0.5$ \\
Platelets $\left(\times 10^{9} / \mathrm{L}\right)$ & $210 \pm 57$ \\
ALT $(\mathrm{U} / \mathrm{L})$ & $40.7 \pm 25.9$ \\
WCC $\left(\times 10^{9} / \mathrm{L}\right)$ & $8.9 \pm 4.2$ \\
CRP $(\mathrm{mg} / \mathrm{L})$ & $11.1 \pm 13.8$ \\
\hline ALT, Alanine aminotransferase; $B N P$, brain natriuretic peptide; $B U N$, blood urea ni- \\
trogen; $C R P, \mathrm{C}-$ reactive protein; $G F R$, glomerular filtration rate; INR, international \\
normalized ratio; WCC, white blood cell.
\end{tabular}

and end-organ function. Some $25 \%$ of patients were in cardiogenic shock at the time of LVAD implantation despite increasing inotropic and additional IABP support (Tables 1 and 2). The high-risk status of the present patient cohort is underlined by deranged preoperative hemodynamics and echocardiographic parameters (Table 2). The mean pulmonary capillary wedge pressure was $25.1 \pm 5.6 \mathrm{~mm} \mathrm{Hg}$ with a mean cardiac index of less than 2 with left ventricular enddiastolic dimensions showing severe left ventricular dilatation with a mean ejection fraction of $21.1 \% \pm 11.1 \%$. Two patients had severe mitral regurgitation at the time of partial-support LVAD implantation. Also, $33.3 \%$ of patients had at least 1 previous sternotomy (range, 1-5), and 1 patient had a previous thoracotomy. Of these patients, 1 had been supported with a full-flow long-term LVAD that was subsequently explanted for myocardial recovery.

Preoperative laboratory parameters are shown in Table 3. The severity of heart failure also can be assessed by the deranged laboratory values indicating impaired end-organ function. Patients had increased mean brain natriuretic peptide, blood urea nitrogen, total bilirubin levels, and slightly deranged alanine aminotransferase. Furthermore, despite the fact that only 1 patient required hemodialysis preoperatively, the mean glomerular filtration rate was moderately impaired and corresponded to stage 3 chronic kidney disease. At the same time, all patients who were not on hemodialysis required preoperative treatment with diuretics (Table 4). The details of preoperative heart failure drugs, platelet inhibitors, and anticoagulants are shown in Table 4.

Postoperative outcomes, including major adverse events after LVAD implantation, are shown in Table 5. In brief, 2 patients required postoperative hemodialysis for renal failure, 1 patient had respiratory failure requiring reintubation, and 2 patients had to be reopened for late chest hematoma after a mean time of $14.5 \pm 4.9$ days. Also,
TABLE 4. Preoperative medication

\begin{tabular}{lc}
\hline \multicolumn{1}{c}{ Drug } \\
\hline ACE inhibitor & $4(33.3 \%)$ \\
Angiotensin II receptor antagonist & $4(33.3 \%)$ \\
Beta-blocker & $9(75.0 \%)$ \\
Amiodarone & $2(16.7 \%)$ \\
Aldosterone antagonist & $4(33.3 \%)$ \\
Loop diuretic & $11(91.7 \%)$ \\
Oral anticoagulants & $3(25 \%)$ \\
Platelet inhibitor & $3(25.0 \%)$ \\
Digoxin & $2(16.7 \%)$ \\
Other antiarrhythmic drug & $1(8.3 \%)$ \\
\hline$A C E$, Angiotensin-converting enzyme. &
\end{tabular}

nondevice-related infections developed in 2 patients over the follow-up. One of them had confirmed bacterial infection from bronchoalveolar lavage on postoperative day 6 , and 1 developed a urinary tract infection that was diagnosed on the postoperative day 12. Both infections were appropriately treated with antibiotics and did not affect long-term outcome. Neurologic dysfunction due to an embolic cerebrovascular event developed in 1 patient, which lasted for more than 24 hours. This patient died on postoperative day 90 , and this death was attributed to general clinical deterioration with a background of multiorgan Fabri's disease, although the device continued to function satisfactorily. Four patients (33.3\%) experienced pump thrombosis and underwent device exchange.

Mild RVF requiring prolonged inotropic support or moderate to severe RVF requiring a right-sided mechanical support did not develop in the patients from the present cohort. Also, there were no significant early postoperative surgical bleeding episodes requiring reopening and no devicerelated infections.

\section{Follow-up and Survival}

The mean support duration was $266 \pm 229$ days. The longest support duration was 764 days, and this patient is still on support and doing well. The overall cumulative survival after partial-support LVAD implantation was $100 \%$ at 30 days and $88.9 \%$ at 6 months, 1 year, and 2 years (Figure 1). Over the follow-up period, 3 patients (25\%) successfully underwent transplantation, 1 patient underwent LVAD explantation for myocardial recovery, 2 patients $(16.7 \%)$ were upgraded to a full-support LVAD (HVAD, HeartWare Inc), and 5 patients $(44.3 \%)$ are still being supported.

\section{DISCUSSION}

LVADs are being used increasingly for patients with advanced heart failure as a bridge to transplantation in response to waiting list mortality because of the donor heart scarcity. ${ }^{2,3}$ Currently, full-support LVADs still remain the most widely used assist systems. ${ }^{8,9}$ Recent developments in the field of circulatory assist have resulted in the 
TABLE 5. Postoperative outcomes

\begin{tabular}{|c|c|}
\hline Characteristics & Value \\
\hline \multicolumn{2}{|l|}{ Postoperative outcomes } \\
\hline Inotropic support duration (d) & $2(1-7)$ \\
\hline Ventilation duration $(\mathrm{d})$ & $1(1-1)$ \\
\hline Mild $\mathrm{RVF}^{*}$ & 0 \\
\hline Moderate to severe $\mathrm{RVF}^{\dagger}$ & 0 \\
\hline Hemodialysis & $2(16.7 \%)$ \\
\hline Reintubation & $1(8.3 \%)$ \\
\hline ICU LOS (d) & $4(1-12)$ \\
\hline Total hospital LOS (d) & $32(19-90)$ \\
\hline Transfusions (units within 7 d) & $8(2-18)$ \\
\hline $\mathrm{RBC}$ & $0.5(0-3.5)$ \\
\hline Platelets & $0(0-1)$ \\
\hline FFP & $0(0-2.75)$ \\
\hline Need for revision because of postoperative bleeding & 0 \\
\hline Need for revision because of late hematoma & $2(16.7 \%)$ \\
\hline \multicolumn{2}{|l|}{ Infections } \\
\hline Nondevice-related infections & $2(16.7 \%)$ \\
\hline Device-related infections & 0 \\
\hline \multicolumn{2}{|l|}{ Long-term outcomes } \\
\hline Support duration $(\mathrm{d})$ & $266.6 \pm 229.9$ \\
\hline Upgrade to a full-support LVAD & $2(16.7 \%)$ \\
\hline Ongoing support & $5(41.7 \%)$ \\
\hline Died on support & $1(8.3 \%)$ \\
\hline Transplanted & $3(25.0 \%)$ \\
\hline Explanted for recovery & $1(8.3 \%)$ \\
\hline Need for device exchange for device failure & $4(33.3 \%)$ \\
\hline \multicolumn{2}{|l|}{ Neurologic complication } \\
\hline Ischemic CVA & $1(8.3 \%)$ \\
\hline Hemorrhagic CVA & 0 \\
\hline Seizure & 0 \\
\hline TIA & 0 \\
\hline \multicolumn{2}{|l|}{ Other adverse events } \\
\hline Hemolysis & $3(25.0 \%)$ \\
\hline Gastrointestinal bleeding & $1(8.3 \%)$ \\
\hline MI & 0 \\
\hline Wound dehiscence & $1(8.3 \%)$ \\
\hline Venous thromboembolism & 0 \\
\hline Cardiac arrhythmias & $1(8.3 \%)$ \\
\hline \multicolumn{2}{|c|}{$\begin{array}{l}C V A \text {, Cerebrovascular accident; } F F P \text {, fresh-frozen plasma; } I C U \text {, intensive care unit; } \\
L O S \text {, length of stay; } M I \text {, myocardial infarction; } R B C \text {, red blood cells; } R V F \text {, right } \\
\text { ventricular failure; } T I A \text {, transient ischemic attack; } L V A D \text {, left ventricular assist } \\
\text { device. *Requiring inotropic support for }>14 \text { days. } \dagger \text { Requiring right-sided mechani- } \\
\text { cal support. }\end{array}$} \\
\hline
\end{tabular}

successful implementation of miniaturized partial-flow devices intended for patients with severely symptomatic heart failure but preserved end-organ function and no inotropic dependency ${ }^{5-7}$ However, the proportion of high-risk patients requiring inotropic support or IABP before an LVAD implantation has significantly increased in recent years.

This study is a 2-center experience of partial LVAD support as a bridge to transplantation in patients who were dependent on inotropic support with or without an IABP. In the present study, we showed that inotropic-dependent patients may benefit from partial-support devices because partial flow seems to be sufficient even under conditions of low cardiac output. This finding may be attributable to the rapid and less-invasive surgery required for Synergy pump implantation, which may reduce morbidity and mortality normally associated with full-support LVADs (which in most cases is performed through median sternotomy and with cardiopulmonary bypass). This promotes a quick recovery and return to normal activities, and early reinstitution on the transplant waiting list. If the Synergy device needs to be replaced, this is a relatively straightforward procedure.

The Synergy device achieved CE mark approval in Europe in September 2012. This pump was approved only for patients with heart failure graded as INTERMACS class 4 and above. ${ }^{10}$ The device was not originally intended for the treatment of patients with heart failure who are dependent on inotropic support or IABP. Therefore, we describe "off-label" use of partial support in patients with more advanced heart failure.

Over the last 2 decades, the number of full-support ventricular assist devices implanted and the duration of support and survival have increased significantly. ${ }^{11}$ However, the long-term survival remains suboptimal, because LVAD implantation is still associated with an unacceptably high number of postoperative adverse events. ${ }^{4}$ This study demonstrates that even in high-risk patients, the device is associated with a lower rate of early complications, such as surgical bleeding, infections, thromboembolism, and RVF. In particular, freedom from the RVF in all patients from our cohort is a significant advantage of the Synergy device compared with full-support systems. Also, recognized major late complications, such as device-related infections, cerebrovascular events, and development of aortic regurgitation, seem to occur less frequently with the Synergy device than in full-support devices. The only major longterm complication of partial-support devices that has been described and remained a significant limitation of the current study is device failure primarily due to pump thrombosis. However, an even higher incidence of device thrombosis was reported after initial clinical implementation of an intrapericardial continuous-flow, full-support device. ${ }^{12}$ The results of a subsequent retrospective analysis of the explanted pump impellers and the pump manufacturing techniques led to a change in the impeller geometry and tighter specifications for the thrust-bearing dimensions. These technologic changes significantly improved outcomes with significantly less device failures due to thrombosis. ${ }^{12}$ For that reason, further refinement of the Synergy impeller design is likely to result in a further reduction in the rate of pump thrombosis. Also, the development of further partialsupport devices should be conducted focusing on prevention of this major complication. Nevertheless, as described in previous research and confirmed by our experience, the Synergy pump exchange can be performed more easily and quickly than a full-support LVAD, similar to a 


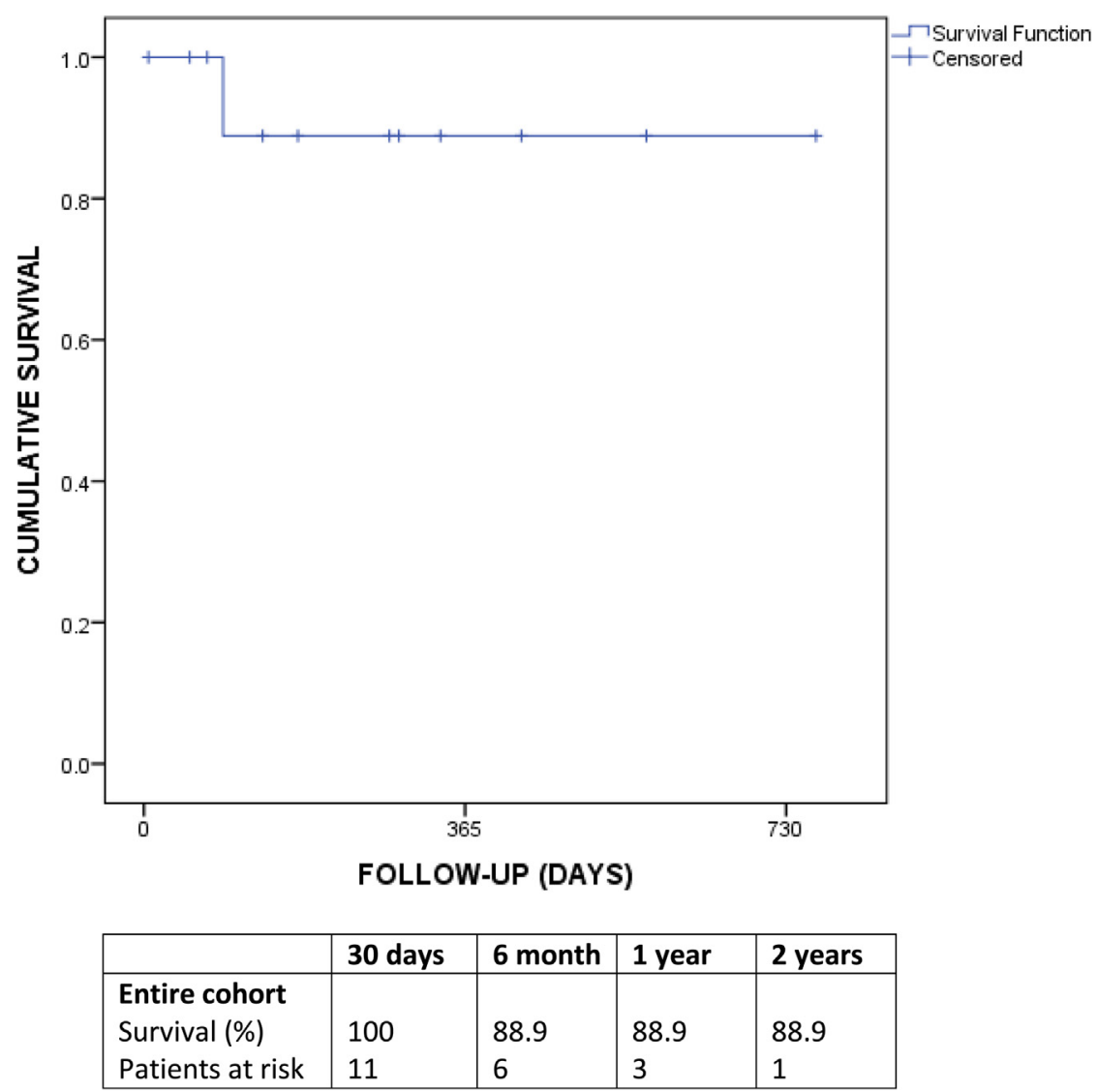

FIGURE 1. Kaplan-Meier survival curve for the entire cohort of patients who underwent partial-support LVAD implantation. Patients are censored for cardiac transplantation, device explantation for myocardial recovery, device exchange, and at the cutoff of the study. Twenty-day, 6-month, 1-year, and 2-year cumulative survivals with respective numbers of patients at risk are shown.

pacemaker exchange, even in difficult clinical settings, because neither sternotomy nor inflow/outflow cannulae exchange is needed. ${ }^{13}$

In general, our outcomes with partial support are similar to those described in previous studies of patients for whom the Synergy device was originally intended, that is, lessadvanced heart failure. However, in our patient cohort, there may be a relatively high risk of the requirement for an upgrade to a full-support device because of late deterioration in hemodynamics and clinical condition. This might be explained by the fact that partial support in "less sick" patients was designed to prevent possible deterioration of relatively stable patients and avoid the need for a full-support LVAD. ${ }^{5-7}$ However, our cohort consisted of patients who were already on inotropic support, with progressive decline in end-organ function or even cardiogenic shock. Nevertheless, as shown in our study, the partial support was sufficient for the majority of patients, and an upgrade to a full-support LVAD was necessary in only 2 patients $(16.7 \%)$. In the first case, the patient who was dependent on IABP and inotropic support preoperatively remained supported with an IABP during the first 5 postoperative days. After unsuccessful attempts to wean off the balloon pump, the decision was made to implant a full-support LVAD through median sternotomy. Because the patient had no previous sternotomy, the upgrade LVAD implantation was similar to a first LVAD implantation and was not considered re-do surgery. However, if the Synergy device is replaced with a full-flow LVAD, care must be taken to ensure the left atrial cannulation site is closed meticulously, otherwise air may be entrained when full LVAD support is initiated. The patient had a rapid subsequent recovery and was placed on our transplant waiting list. Of note, this patient's low weight and relatively well-preserved preoperative cardiac output were considered as reasons for proceeding with partial support, but despite this, he subsequently required full support.

In the second case, the partial support was successful for approximately 4 months, and the patient was discharged. Nevertheless, an upgrade to full support had to be performed after sudden deterioration in cardiac function with rapidly increasing heart failure symptoms. After fullsupport LVAD implantation, the patient was discharged and subsequently placed on our transplant waiting list and underwent transplantation. Despite the fact that this patient was free of inotropic support after partial support had been 
implemented and was discharged with approximately 4 months of uneventful follow-up, we do not consider this case a clinical success because the patient was not bridged to transplantation with only partial support. However, it might have been considered successful if we had received a suitable organ offer during this uneventful timeframe on Synergy pump support. Both examples show that an upgrade of partial-support LVAD to a full-support LVAD might be necessary in individual patients. Because of a low number of cases with partial support in inotropic/ IABP-dependent patients and no obvious reasons for deterioration, the predictors of early or late upgrade to a fullsupport LVAD warrant further investigations.

Because the Synergy pump is located outside the pericardium, the sternotomy and excision of the native heart during the heart transplantation are not associated with extensive and time-consuming dissection and may significantly decrease the total ischemic time, which is advantageous. The pump can be stopped and excised before or after implanting the donor heart. Furthermore, in case of primary graft failure, it is conceivable that the Synergy pump could be restarted to temporarily support the donor heart before weaning and explantation at a later date.

In the present study, the survival was $100 \%$ at 30 days and $88.9 \%$ at 1 and 2 years, which is not inferior, if not better, than the survival in patients in full-flow LVAD trials. $^{5-7}$ These results demonstrate that the novel device configuration can be clinically efficacious even in patients with more advanced heart failure, and that the partialsupport idea has a potential utility in a wide range of patients with severe heart failure. Despite recently reported technical issues regarding the Synergy Pocket Micropump $^{14}$ and the need for improvement in the pump thrombosis rate, the general idea of partial support seems to be a valuable option for patients with heart failure. Furthermore, our preliminary evidence suggests that partial flow might be sufficient even in patients with low cardiac output. Additional benefits due to the less-invasive access, fewer complications, and a lower cardiac transplantation risk might precipitate an increasing use of partial-support devices. In summary, the current answer to the question: "Do we still need full-support LVADs?" is "Yes, we do." However, potential technologic improvements and development of new reliable devices may significantly increase the proportion of patients with heart failure who can be bridged to transplantation using partial-flow LVADs. However, because there is a risk of deterioration on partial support, the need to refine patient selection criteria particularly in cases with more advanced heart failure remains an important target for further investigations.

\section{Study Limitations}

A 2-center experience with a small cohort of patients has been presented. However, the total number of Synergy devices implanted in patients worldwide is comparatively small. Furthermore, this device is currently undergoing an upgrade to resolve issues that arose after initial commercial release. Surgical system sales are expected to resume in a controlled fashion after regulatory approval to relaunch the system in Europe.

\section{CONCLUSIONS}

Partial LVAD support may be clinically efficacious in inotropic and IABP-dependent patients. On the basis of our experience and evidence of previous research, such patients may benefit from minimally invasive access, no need for sternotomy and cardiopulmonary bypass, a short implantation time, an easy exchange if necessary, and a lower risk of subsequent heart transplantation. Because the implantation is performed without sternotomy, device upgrade is feasible with a comparatively low operative risk and good clinical outcome. Our preliminary results show that partialsupport devices may have the potential to replace full-support LVADs in the near future.

\section{References}

1. Slaughter MS, Rogers JG, Milano CA, Russell SD, Conte JV, Feldman D, et al Advanced heart failure treated with continuous-flow left ventricular assist device. N Engl J Med. 2009;361:2241-51.

2. Goldstein DJ, Oz MC, Rose EA. Implantable left ventricular assist devices. $N$ Engl J Med. 1998;339:1522-33.

3. Popov AF, Hosseini MT, Zych B, Mohite P, Hards R, Krueger H, et al. Clinical experience with HeartWare left ventricular assist device in patients with endstage heart failure. Ann Thorac Surg. 2012;93:810-5.

4. Sabashnikov A, Mohite PN, Simon AR, Popov AF. HeartWare miniaturized intrapericardial ventricular assist device: advantages and adverse events in comparison to contemporary devices. Expert Rev Med Devices. 2013;10:441-52.

5. Meyns B, Klotz S, Simon A, Droogne W, Rega F, Griffith B, et al. Proof of concept: hemodynamic response to long-term partial ventricular support with the synergy pocket micro-pump. J Am Coll Cardiol. 2009;54:79-86.

6. Meyns BP, Simon A, Klotz S, Wittwer T, Schlensak C, Rega F, et al. Clinical benefits of partial circulatory support in New York Heart Association Class IIIB and Early Class IV patients. Eur J Cardiothorac Surg. 2011;39:693-8.

7. Klotz S, Meyns B, Simon A, Wittwer T, Rahmanian P, Schlensak C, et al. Partial mechanical long-term support with the CircuLite Synergy pump as bridge-totransplant in congestive heart failure. Thorac Cardiovasc Surg. 2010;58(Suppl 2); S173-8.

8. Sheikh FH, Russell SD. HeartMate(R) II continuous-flow left ventricular assist system. Expert Rev Med Devices. 2011;8:11-21.

9. Lahpor JR. State of the art: implantable ventricular assist devices. Curr Opin Organ Transplant. 2009;14:554-9.

10. Yoshioka D, Sawa Y. [Clinical results of continuous-flow left ventricular assist device (LVAD) for severe heart failure patients]. Kyobu Geka. 2013;66:57-61.

11. Emin A, Rogers CA, Parameshwar J, Macgowan G, Taylor R, Yonan N, et al Trends in long-term mechanical circulatory support for advanced heart failure in the UK. Eur J Heart Fail. 2013;15:1185-93.

12. Wieselthaler GM, O Driscoll G, Jansz P, Khaghani A, Strueber M. Initial clinical experience with a novel left ventricular assist device with a magnetically levitated rotor in a multi-institutional trial. J Heart Lung Transplant. 2010; 29:1218-25.

13. Bireta CST, Sabashnikov A, Danner BC, Grossmann M, Zenker D, Muehlhaeuser U, et al. Challenging treatment of an infected CircuLite micropump after pump thrombosis due to subtherapeutic anticoagulation therapy. Pushing the limits? Artif Organs. August 8, 2013 [Epub ahead of print].

14. Schmack B, Gorenflo M, Rengier F, Ruhparwar A. Extempore interventional closure of a broken CircuLite Synergy micropump inflow graft defect. $J$ Heart Lung Transplant. 2013;32:1140-1. 


\section{Discussion}

Dr Kavous Hakim-Meibodi (Bad Oeynhausen, Germany). Thank you, Dr Sabashnikov, for presenting your work pushing the limits on the treatment of very ill patients with failing left ventricular function. Since the first implantation of the device in 2008, it has been on and off the market several times for technical problems. Finally, the CE mark was achieved in 2012.

In your current study, you have achieved some remarkable results using this device for very ill patients, INTERMACS class I to III. I congratulate you on these results. On the other hand, perhaps some of the reported results need some second thought.

You reported the variety of patients in INTERMACS class I to III. What were the criteria to use this device for this kind of patient instead of the full LVAD?

Dr Sabashnikov. At that time, we didn't have any data on using this device in patients with INTERMACS classes higher than IV because the device was actually approved for less sick patients without inotropic dependency.

However, we thought some patients would benefit from this device, and we implanted it preferably in patients with low body mass index and with deterioration that had started recently with still available cardiac output. Because our idea was that despite low flow of a maximum of 4.25 liters, this support was being added to the remaining cardiac output of patients. Cardiac output was enough for most of them. That was the main idea why we started using the device in inotropic-dependent patients.

Our results showed that only $16 \%$ of patients had to be upgraded. As I mentioned, the risk of upgrade is lower because it's the first sternotomy, and it should not be considered a redo procedure.

Dr Hakim-Meibodi. Four of 12 patients had pump thrombosis. In my opinion, this is a high rate. I guess it's device related. How did you proceed? Did you just exchange the pump or also the inflow part, which is intrathoracal?

Dr Sabashnikov. Device thrombosis is the most important part of this story because a high number of complications occurred. However, the device is new, and I have to mention that other devices had similar problems in the beginning, and after several manufacturer changes, the quality of the devices improved.

So now we are in the phase when this device is being refined. Some manufacturer changes are being performed, and we hope that next year we will have a completely new version of this: a partial-support device with significantly lower risk of thrombosis. In all cases, we treat thrombosis by exchanging the device because it's a short and easy procedure. In all cases, we leave the inflow cannula in situ. However, we left the clamp open for a couple of seconds to be sure that the cannula is free of thrombi.

Dr Hakim-Meibodi. Don't you think this small inflow cannula far from the pump is one of the reasons for the thrombosis, the systematic problem for this device?

Dr Sabashnikov. No. According to our investigations, most thrombotic structures occurred in the pump itself, so we were not really worried about the cannula.

Dr Hakim-Meibodi. Don't you think this high rate of thrombosis is particularly dangerous in this pump-dependent group of patients? So this is something that is well tolerated if the patient has enough rest output, but if he's depending on the pump, it could be a severe problem.
Dr Sabashnikov. Sure. We were lucky that all pump thromboses occurred when patients were still in the hospital, and patients theoretically might have been put on inotropic support, but we managed to do it without. Nevertheless, that's a good point that inotropic-dependent patients might deteriorate because of low cardiac output, at home if they develop pump thrombosis and still have not recovered at least a little bit. However, it can happen with any device.

Dr Hakim-Meibodi. You reported 1 patient who already had an LVAD. What were the criteria to implant this pump in this patient and what did you do to the assist device? Did you explant it?

Dr Sabashnikov. It was a young patient who had undergone implantation with a full-flow assist device via median sternotomy a long time ago, and he underwent explantation of the assist device because of myocardial recovery later and was free of heart failure symptoms for a long period of time. Once he developed heart failure symptoms again and was deteriorating, we decided to go for a less-invasive procedure because of the previous full sternotomy.

Dr Nader Moazami (Cleveland, Ohio). The concept of partial support is interesting, specifically in the very sick patients who have received this device. I think we always use the yardstick of survival as a measure of success.

What I didn't see in your presentation is how do the hemodynamics of these patients improve? What was the functional status of these patients? Were any discharged or were they in the hospital all the time?

The reason I say that is because, as you know, this technology is now off the shelf because of multiple problems. Thrombosis is just one of the problems. There are many other problems, and there are other pumps that can now be implanted through minithoracotomies that can provide full support. So we should be careful, specifically because of the bad experience with left atrial cannulation in general. What was the functional status of these patients?

Dr Sabashnikov. One patient died. All other patients underwent transplantation or are on ongoing support, and all of them were discharged.

Regarding your good points, we are now in the beginning area of this partial support and already have seen results. Thrombosis and other complications that occurred during LVAD support in the beginning are normal signs, and that's why the device is temporarily suspended. But our general idea is not related to this particular device but to the partial support in general. So people can use this information after development of new partial-flow devices, and particularly after the Synergy device has been upgraded to a better model and is available on the market again.

Dr Oztekin Oto (Izmir, Turkey). You mentioned that you had no RVF at all, although you are partially supporting and these are very ill patients. What is the secret then, and what are your RVF criteria?

Dr Sabashnikov. We are not sure, but it might be related to the low transfusion rate because it's a less invasive procedure without sternotomy. Also, it's a short implantation with lower trauma. But it's still unclear, because it's a very new area.

Dr Jose Pomar (Barcelona, Spain). Just to tell you, the next time, please remember that not everybody knows what the Synergy pump is, and it would be nice to have a picture at the beginning. 